\title{
Mapping Community Capitals: A Potential Tool for Social Work
}

\author{
Kyle A. Pitzer \\ Calvin L. Streeter
}

\begin{abstract}
Concept mapping can be a useful tool in social work practice at all levels. Mapping can help clarify and increase comprehension of abstract concepts, such as community capitals or assets. This paper describes community capitals, presents a simple method for mapping community assets conceptually, and demonstrates this method through two case examples. The cases detail activities of two organizations involved in work with communities. The development and leveraging of capitals is illustrated in both instances. Following the case examples, the significance and value of mapping in social work and suggestions for future research are discussed based on the mapping exercise.
\end{abstract}

Keywords: Community development, community capitals framework, community practice, concept mapping, social work practice

Social workers play a vital role in the assessment of social issues, the implementation of interventions, and the evaluation of interventions. These activities take place at multiple levels of practice including micro, mezzo, and macro levels. The Community Capitals Framework (CCF) can be a useful conceptual tool for social workers in various practice settings and at multiple practice levels, especially the community level, where engaging community members in the process of identifying, leveraging, and building community resources is critical. The CCF fits logically with many models for community assessment and can be useful in planning and implementing community interventions. Traditionally, mapping changes in community capitals has been visualized as an upward spiral. Here we present a different style of mapping that can be easily interpreted and used by social workers and the communities with which they work to gain insights into the assets that exist in the community and how those assets might be used to enhance community capacity. This paper illustrates the mapping of community capitals in social work practice by including the interventions and community activities that are directly involved in building capital. By carrying out this exercise, the intention is to provide some examples that social workers can adapt to their own practice areas to benefit the individuals, groups, and communities they serve. In this paper, the CCF is briefly defined, the mapping method is outlined, and examples are presented to illustrate how community capitals are built and leveraged in different settings and through different approaches. Lastly, the utility and importance of mapping community capitals is discussed as well as the role of intangible capitals in community development using capital maps as a reference.

\section{Community Capitals Framework and Community Interventions}

The term capital is most frequently found in economics and refers to "money or assets" that are invested to yield economic outcomes (Bishop, Press, \& Tauber, 2010, p. 54). Capital, in the context of the CCF, represents a range of resources found within a

Kyle A. Pitzer, MSSW, is a doctoral student at Washington University in St. Louis, George Warren Brown School of Social Work. Calvin L. Streeter, PhD, is the Meadows Foundation Centennial Professor in the Quality of Life in the Rural Environment at the University of Texas at Austin School of Social Work. 
community that can be invested to grow other capitals and benefit the community (Flora \& Flora, 2013). The Community Capitals Framework outlines seven major types of assets that may be present in communities. These types of assets, detailed in Table 1, are natural, cultural, human, social, political, financial, and built (Flora \& Flora, 2013). According to Flora and Flora (2013), every community has some degree of resources, and these resources can be leveraged to develop additional resources, or capital. The authors also assert that the ultimate goal of every community is to become sustainable, which can be achieved by developing and leveraging community capitals. A sustainable community is defined as one that is economically secure, socially inclusive, and ecologically healthy (Flora \& Flora, 2013).

\begin{tabular}{ll}
\hline \multicolumn{2}{c}{ Table 1. Seven Capitals in the Community Capitals Framework } \\
\hline Natural Capital & $\begin{array}{l}\text { Elements of nature present in a community including land and water } \\
\text { resources, weather, and biodiversity }\end{array}$ \\
Cultural Capital & $\begin{array}{l}\text { Values and perspectives of community members that play a major role } \\
\text { in self-efficacy in affecting community change }\end{array}$ \\
$\begin{array}{l}\text { Human Capital } \\
\text { Social Capital }\end{array}$ & $\begin{array}{l}\text { Trust, collaboration, and shared vision among community members } \\
\text { Political Capital }\end{array}$ \\
$\begin{array}{l}\text { Ability of groups or communities to influence policy and ensure that } \\
\text { policies are implemented accordingly }\end{array}$ \\
Financial Capital & Monetary resources \\
\hline
\end{tabular}

(Flora \& Flora, 2013)

The CCF can easily be used alongside other models or theories that are commonly employed in social work practice. Previous mapping of community change using the CCF focuses on a systems perspective (Emery \& Flora, 2009). Mapping community capitals using the systems perspective is critical to social workers in assessing community capitals and guiding community intervention. Alternatively, mapping that provides more detail in the illustration of interventions and activities of interest to social workers in the field could be useful as well.

Interventions that can be guided by the CCF take various forms. For example, several studies have shown that investments in leadership development can generate a great amount of community benefit (Allen \& Lachapelle, 2012; Apaliyah, Martin, Gasteyer, Keating, \& Pigg, 2012; Emery, Fernandez, Gutierrez-Montes, \& Flora, 2009). Apaliyah et al. (2012) found that participants in leadership training across six different states implemented over 200 community projects that enhanced each of the seven capitals. Furthermore, most of the activities impacted more than one of the capitals resulting in multiple gains from a single project. This demonstrates that developing human capital can also generate gains in other capitals through community-based projects implemented by community members.

Social capital within communities is also crucial to developing other community capitals. Bourdieu (1986, p. 248) defined social capital as the aggregate of resources, "actual or potential," to which one has access by possessing "membership in a group." 
Coleman (1988) further implied that social capital plays a unique role in the development of other common forms of capital. More recently, bonding social capital has been defined as the connection between individuals in similar circumstances, and bridging social capital has been defined as the connection between groups within and external to communities-exclusive and inclusive, respectively (Flora \& Flora, 2013; Putnam, 2000; Putnam \& Feldstein, 2003; Woolcock \& Narayan, 2000). Both of these types of social capital have been cited as important to sustainable communities and are useful for producing different kinds of community outcomes (Flora \& Flora, 2013; Putnam, 2000). An additional type of social capital that has also been cited is linking social capital, which is the connection between communities and other formal institutions that hold some position of power (Woolcock, 2001). Social capital has also been discussed to an extent in the field of social work (see Dominguez, 2008; Hawkins \& Maurer, 2012; Healy \& Hampshire, 2002; Overcamp-Martini, 2008). Given the importance and interconnectedness of both bonding and bridging social capital, as well as the impact of social capital on other capitals, understanding the assessment of social capital as well as interventions that can further enhance it is essential for communities hoping to build community capitals.

Social capital can be both a result and driver of community intervention. For instance, in a study of community capitals in one community development project described by Emery and Flora (2009), a critical component of development was increasing social capital. Social capital was also recognized as one of the primary facilitators. The initiative focused on developing leadership, entrepreneurship, and philanthropy. Existing leaders leveraged bonding social capital to initiate development, and social capital was then increased through the engagement of community members and external partners in the process. One example of this engagement is the provision of opportunities for youth and adults to work together on each facet of the development strategy. Connecting these two age groups contributed to the regeneration of the community by retaining and developing the human capital found in the youth and using it within the community. The implementation of these types of activities resulted in enhanced community capitals. In this case, the community achieved gains in human, social, political, cultural, and financial capital, unfolding from the beginning of the intervention. Although this is only one case, it offers an idea of the types of interventions that influence community capitals and how the CCF can be used in design and planning processes.

The main objective of this paper is to present a method for mapping community capitals conceptually in a way that can be harnessed by social workers involved in practice with communities to bring about community change. The authors' primary goals in writing this paper are to illustrate the viability of the CCF for social workers and provide an easily replicable and adaptable concept mapping approach that can be used by social workers and the communities with which they work. Given that social workers are concerned with assessment, intervention, and evaluation, this method can be used in multiple phases: assessing which community capitals are present or needed, determining how to enhance them, and examining the impact of these strategies on community capitals. Two case examples are presented to illustrate how community capital can be increased, as well as the actions that contribute to those enhancements. The cases are then mapped using the CCF 
as a guide to illustrate the outcomes as well as the interventions and community activities to serve as a reference for social workers.

\section{Concept Mapping}

Different types of mapping have been successfully used in community practice to a variety of ends. Typically, mapping is thought of as depictions of locations of attributes in geographic space. In this case, the authors are mapping abstract concepts rather than physical space, in order to track changes in community capitals. Concept mapping tools can be used to identify assets, plan and guide implementation of community projects, or evaluate and reflect on community change efforts that have taken place within a specific community (see Davis \& Cooper, 2014; Kane \& Trochim, 2007; Trochim, Milstead, Wood, Jackson, \& Pressler, 2004). For each of these purposes, a map can provide a simple and neat illustration of the major components of the task at hand. Concepts related to community development, such as community capitals, can be somewhat abstract and difficult to understand. Mapping community capitals as they are developed through the programs and activities of community members can potentially enhance both social workers' and community members' understanding of these concepts as well as their selfefficacy in using this type of framework to improve communities.

The mapping exercise presented in this paper was developed in order to clarify the concept of community capitals within communities and how these capitals are affected by social work practice. The maps are simple hybrids of the traditional spiraling up approach and concept mapping, which is used in various disciplines and professions. The maps are shown as flowing upward in order to emphasize the gain in capital, and consequently, the development of the target community. The capitals are contained within ovals, similar to several types of concept maps. Arrows accompanied by the intervention or community activity are used to illustrate the activities associated with each capital gain. The maps are intended to be straightforward and easy to read to demonstrate that this technique can be adapted to and replicated with a variety of communities.

The authors also speculate that this type of concept mapping exercise could enhance community engagement in development activities. Community participation has been recommended as a key component of successful community development (Kretzmann \& McKnight, 1993). A major part of community participation is collaborative and open communication and sharing of information (Botes \& van Rensburg, 2000; Gaunt, 1998; Mannarini \& Talò, 2013). At times, the implementation and impact of community development activities is not readily apparent to the greater community and can seem nonexistent or minimal based upon the experiences of community members. Mapping the development of community capitals along with the activities by which they were developed can serve to clarify the impacts and narrow the gap of knowledge between the community at large and those directly involved in community development projects. These types of concept maps may also be straightforward enough to be used with diverse audiences. This can be critical to generating support from the community and sustaining community development by ensuring there is an understanding among community members regarding development projects and the activities and impacts these projects entail, although more research is needed to explore this idea. 


\section{Case Examples}

The following case examples illustrate and integrate the concepts of the CCF and include community capital maps for each case. Both of the examples are based on internships performed by a social work student placed at the organizations for educational purposes. The maps were generated after the experience for the purpose of this conceptual exercise, and some extrapolation has been used and hypothetical information added to supplement areas where direct evidence was not available. The first example is set domestically with a non-profit organization that manages programs and services for refugees, and the second takes place with a nongovernmental organization (NGO) that focuses on community development in rural India. It is important to note that this is not necessarily a step-by-step guide to mapping community capitals. These examples provide some idea of what mapping community capitals might look like.

\section{Case \#1: Refugee Resettlement in the United States}

The first example focuses on a specific project conducted by an organization specializing in refugee resettlement in the United States. The role of the organization was to provide technical assistance to a local ethnic community-based organization (ECBO) in order to build the capacity of the organization and expand the services available to benefit the greater refugee community. Throughout the project, specific capitals were leveraged and increased, as shown in Figure 1, to benefit the target community through a variety of tasks carried out by the resettlement organization and the ECBO.

The first step in building capital within the refugee community as a whole was to gain support from the various ethnic groups that made up the greater refugee community. The refugee community targeted by the project was somewhat fragmented, though each ethnic group was rich in bonding social capital. To ensure the success of the project, developing bridging social capital was critical. The central task in building this type of social capital was connecting different refugee groups and encouraging conversation about the needs of group members and the goals they hoped to attain. The ECBO was used as a hub for these activities to connect the groups and served as a common meeting ground for hosting productive conversation. Activities related to this task included meetings between ECBO leaders to encourage the development of common goals and objectives and focus groups with community members that were planned and facilitated by technical assistants in order to establish their needs. By helping community leaders recognize commonalities and bringing some of the larger groups together in conversation regarding their needs, cohesion was increased, partnerships were formed, and a shared vision was developed. 
Figure 1. Concept Map Showing Community Capital Development within the Refugee Community

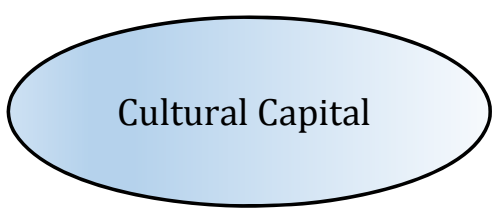

The community members feel more confident in their ability to shape their future
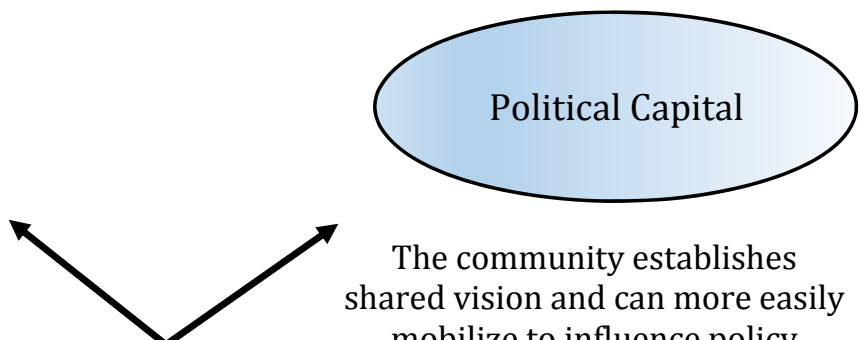

The community establishes shared vision and can more easily mobilize to influence policy
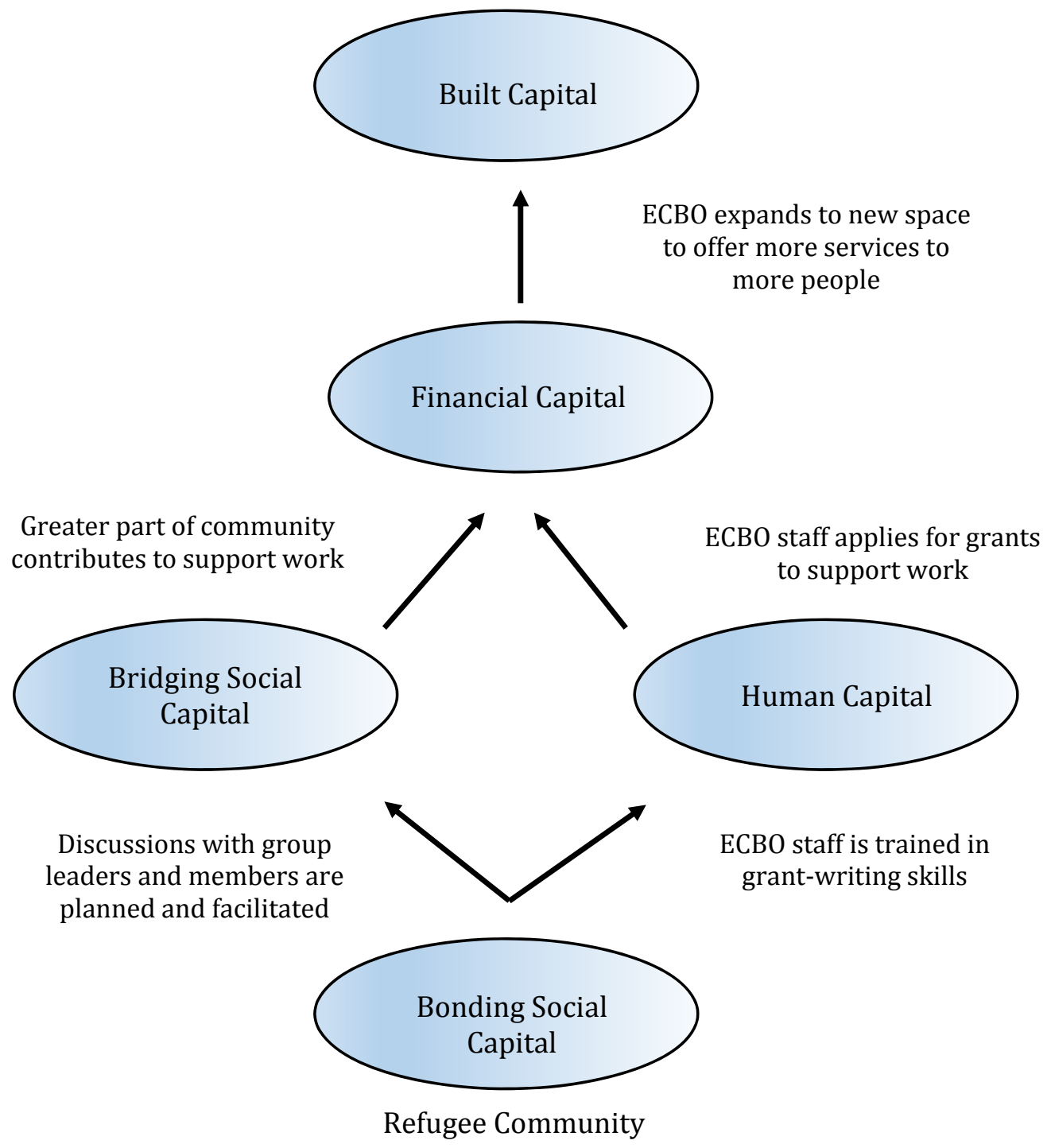
As a twofold approach, human capital within the targeted community was increased as well. Human capital was enhanced within the ECBO and its newly established partners. The skills that fall under human capital most pertinent to this case were those related to the operation of a non-profit organization that provides direct services. Specific focus was given to writing grant proposals. At the beginning of the project, the ECBO was a subgrantee of the resettlement organization, and one of the major goals of the ECBO was achieving self-sufficiency, specifically in terms of funding. The staff received individual technical assistance in completing grant proposals for numerous funding sources. With this technical assistance, the staff members, some of whom were already well-versed in financial matters, were able to apply their knowledge in combination with their newly developed skills to writing grants, resulting in more successful grant proposals.

With the increase in human and social capital, gains in financial capital could be realized. Financial capital was made available through two pathways. The first resulted from the increased social capital. Prior to the work done by the resettlement agency, the ECBO received a small portion of monetary assistance in the form of contributions from the primary ethnic group. It could be extrapolated that as the other ethnic groups became more committed to the advancement of the greater refugee community, the ECBO had access to additional contributions from these groups, supplementing the pool of donated funds. The ECBO could also begin receiving funding through grants. The increase in human capital gave the staff the skills they needed to secure grants through successful grant proposals. The additional financial capital available to the ECBO could be put toward various organization-related purposes such as program development, office expansion, and hiring new staff from other ethnic groups. Although the ECBO planned to use funding to this end, it would also benefit the community in that the ECBO would be able to reach more members of the refugee community with more comprehensive services and increase community cohesion through the hiring of multiethnic staff.

The ECBO also planned to use some of the financial capital to enhance built capital. This would be a small gain relative to the other capitals, but it would be important to the advancement of the community. The built capital would come in the form of new space acquired by the ECBO through which they could provide more services. The new space would be at another location and would be easily accessible to community members who may not have been able to reach the primary office. Again, although the space would belong to the ECBO, the greater community would also benefit in that more people would be able to access services.

Lastly, based on the strides made by the ECBO, and subsequently the community, it can be inferred that both cultural and political capital was positively impacted. A major component of cultural capital is the confidence of community members in their ability to affect the future of the community (Flora \& Flora, 2013). With the accomplishments detailed in this case-- the newly developed skills, organizational partnerships, and social cohesion-- community members likely felt much more confident in their ability to identify challenges and take the appropriate action to address them. In regards to political capital, as the ethnic groups began to recognize their common needs and shared goals, the cohesion of and commitment to the community likely improved. With the increased social cohesion 
and community commitment, it is possible that the greater refugee community could stand united and shape policy in their favor if the need were to arise.

\section{Case \#2: Rural Development in India}

The second example focuses on the community development efforts of a large NGO in South India. The community development program is focused on capacity building and community empowerment around a number of issues. The NGO at hand primarily focuses on rural communities in India, particularly those that are impoverished and marginalized. Some of the major activities of this program are improving governance, assisting in the acquisition of resources both financial and built, raising awareness about community issues, and training community members in policy analysis, evaluation, and development. Figure 2 illustrates these and other activities associated with community capital development. The NGO focuses on issues that are identified by community members as common between rural communities in the same block, district, region, and state.

Many of the rural communities in India with which the NGO works are rich in both bonding and bridging social capital. Community participation in development efforts carried out by this NGO is close to $100 \%$ in many of the communities. In the communities this NGO serves, the problems of individual community members are seen as community issues and are addressed as such. For instance, small community funds exist to assist families and individuals who are in need due to various circumstances, such as loss of income due to injury, disability, or death. There has also been a hierarchy created through the NGO and community leaders that illustrates the bridging social capital of rural communities. The hierarchy begins at the village level and continues to the block, district, region, state, and national level. As villages experience common problems, such as lack of access to fresh drinking water or pollution by multi-national corporations, these problems move up the hierarchy to be addressed at higher levels. 
Figure 2. Concept Map Showing Community Capital Development within Rural Communities in Southern India

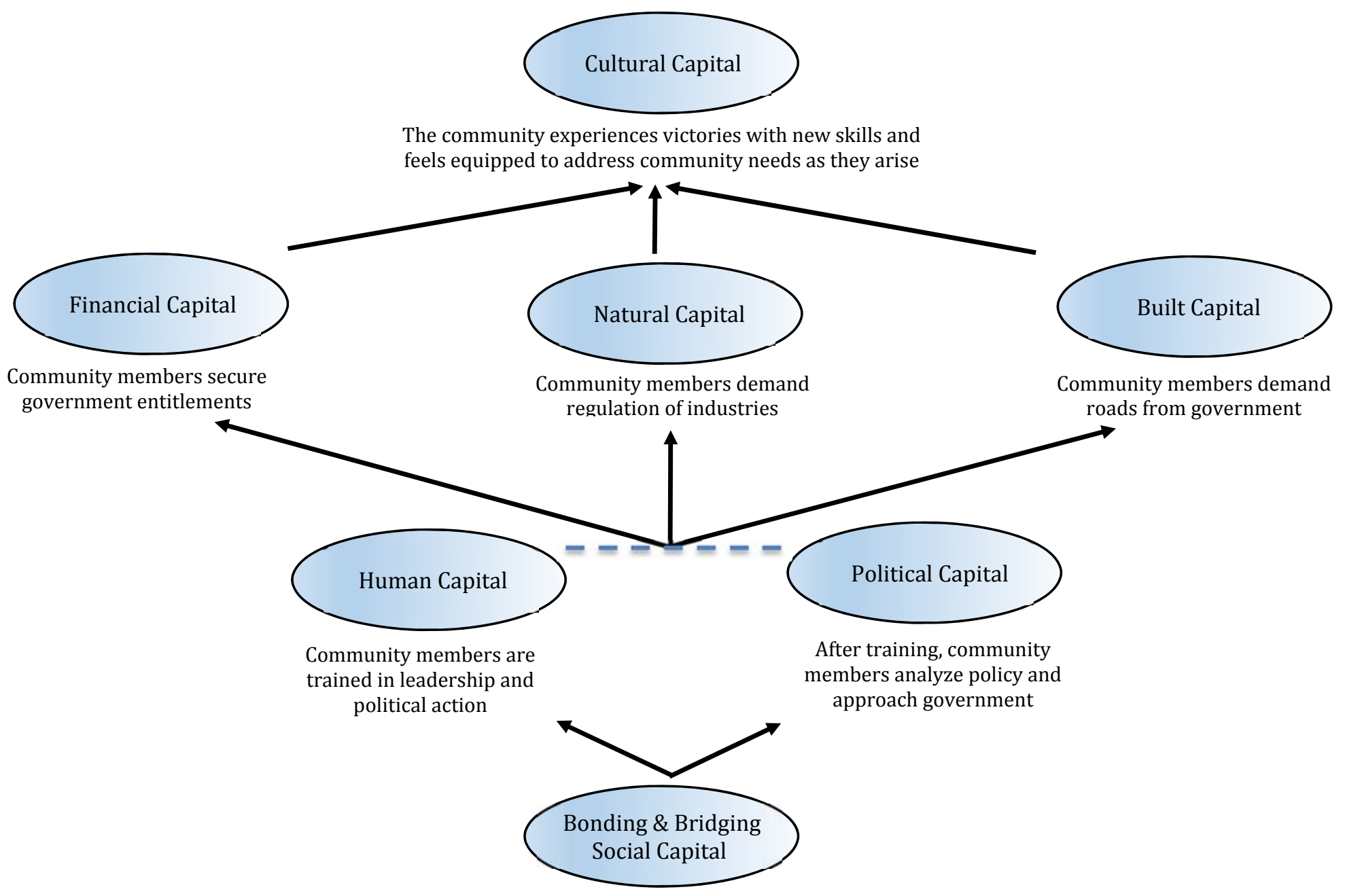

Rural Communities in Southern India 
Building human and political capital is at the core of the development program. A major part of the NGO's work is training community members in policy analysis and evaluation. The community members identify policies that adversely impact them, and the NGO works with the community to analyze those policies and develop recommendations, which are then submitted to the appropriate policy-making bodies. This gives community members a voice in policy at multiple levels of government while improving their individual skills. The community members, aside from being informed about policy, also learn how to approach government representatives and access resources through the government, which is again building both the skills of the individuals and the political capacity of the community.

As a result of the increases in human and political capital, financial capital is gained, natural capital is protected and developed, and built capital is acquired when necessary. Instead of duplicating services provided by other entities, the NGO devotes their efforts to developing the capacity of communities to secure resources through existing avenues such as the government. For instance, the NGO works alongside many community members to inform them about and attain entitlements available through the government, strengthening the financial capital in the community. These entitlements include old age benefits, disability, and survivor benefits. Also, by developing the capacity of community members to approach government officials and access necessary resources, the communities are able to protect their natural capital. In some of the policy workshops, both the speakers and community members discussed how the lack of regulation of some industries results in the pollution of rural villages, destroying crops and other natural resources. As the community members become familiar with approaching government officials and making demands, they are able to leverage their political capital to call for the regulation of industries by government and control the detrimental effects of pollution. In the same vein, community members are able to demand infrastructural improvements for their communities when necessary. An example would be the construction of roads by the government at the request of rural communities to help them become more connected to major cities.

Similar to the previous case, it can be inferred that the capital gains outlined in the previous section have had a dramatic impact on the cultural capital of rural communities in India. This increase in cultural capital was discussed in many community meetings attended by the authors. The NGO in this example has been working in rural communities for decades building community capacity. The many victories experienced by rural communities in India alongside the NGO have likely increased cultural capital. The community members have transformed their communities in many ways and likely feel much more in control of their future and confident in their ability to affect change.

\section{Discussion}

The major points discussed here are the utility and importance of mapping community development concepts, such as community capitals, in community practice and the role of intangible capitals in the development process. The idea of community capitals is abstract and the development of community capitals can be difficult to understand. The two case examples presented here vary in many ways, but these maps illustrate that the development of capitals can be relatively easy to understand. This is important to note because both of 
the communities, as well as the interventions and community activities, are quite different, yet each map gives a clear visualization of what was accomplished in each case. The mapping technique can be used to help communities evaluate their activities and outcomes, identify ways to sustain the capital gains, or plan and guide future interventions for multiple community-wide issues. Despite the fact that these communities are very different, using this relatively simple mapping technique can heighten the comprehension of complex social problems and concepts such as community capitals and the types of activities relevant to community development. This could also be integrated into the macro practice curriculum as along with organizational development, program development, and community organizing. This mapping exercise can be taken as a limited form of preliminary evidence of the viability of this tool in other communities around the world, although research is needed to understand exactly how social workers and community members perceive, understand, and use it. Given the limitations of this exercise - it is retrospective, based on two specific experiences, uses some extrapolation and hypothetical information, and is more similar to evaluation -- the process may look different when implemented with other communities or in other phases of practice, such as assessment and planning.

The traditional idea of community development devotes attention primarily to supplementing funds and facilities that improve physical infrastructure in communities (Emery \& Flora, 2009). These examples and mapping exercises suggest that intangible capitals, such as social, human, and political capital, are also significant to effective, efficient, and sustainable community development. In examining the community capital maps, intangible capitals typically precede tangible capitals. Based on these experiences, enhancing intangible capital can lead to more sustainable and continuous community development outcomes. Developing intangible capital gives communities transferrable skills and assets that can be applied to multiple community needs. Research examining this type of capacity building through social work practice can be beneficial. This is clear in the example regarding rural communities in India and the increases in political capital. The rural communities leveraged this capital for more than one purpose: demanding the construction of roads, calling for the regulation of industries that were polluting their land, and securing government entitlements. The political capital that is leveraged in these instances can also be leveraged in other circumstances as issues arise rather than just acquiring an isolated financial or built capital gain.

The growth of intangible capitals can also give communities a greater sense of ownership and control of their own development. Lachapelle (2009) provides three facets of the concept of "sense of ownership." These are (a) "ownership in process," having a voice in development, (b) "ownership in outcome," having control over the outcome through decision-making, and (c) "ownership distribution," how the outcomes of interventions are distributed among members of the community (Lachapelle, 2009, p. 53). Developing intangible capitals could be equated with capacity-building in relation to the three types of ownership, and ownership in general, as outlined by Lachapelle (2009). This is illustrated by the examples outlined in the mapping exercise.

Based on the presumed gains in cultural capital described in the case examples, it can be reasoned that both of the communities felt a stronger sense of control and ownership in 
their own development by the end of the mapped development processes. In both cases, the initial building of intangible capitals allowed for greater opportunity for involvement and control in the capital building that followed, demonstrating ownership in the process. Secondly, both communities exhibited ownership in the outcomes by choosing to apply their newly found skills for the good of the community. Although the agencies worked alongside the communities, the community members were responsible for identifying the issues as well as carrying out the actions to address them. Finally, the ultimate goal for both communities involved strengthening the community as a whole. Through the various activities performed by participants, the needs of the greater community were addressed, thus distributing the positive effects and benefits to all community members.

\section{Conclusion}

The two examples and maps that have been developed through the lens of the CCF are diverse in a variety of ways. This speaks to the CCF's applicability to many types of social work practice, such as organizational development, program management, and community organizing as well as practice in both domestic and international settings. The types of activities and programs as well as the starting points also vary between the examples. The first focuses on capacity building of a specific organization, and the other concentrates on individual and community capacity development. Furthermore, the fact that both of the examples presented in the mapping exercises came from experiences in social work practice provides greater support for the notion that the CCF can be of great use to social workers. Social workers should be encouraged to modify and adapt this exercise for use in their own practice areas. Additionally, through further research regarding assessment and intervention in terms of community capitals, this type of mapping on a greater scale can be useful in working with communities in various capacities as well as determining a relationship between intangible capitals and successful community development in social work practice.

\section{References}

Allen, R., \& Lachapelle, P. (2012). Can leadership development act as a rural poverty alleviation strategy? Community Development, 43(1), 95-112. doi: http://dx.doi.org/10.1080/15575330.2011.645046

Apaliyah, G., Martin, K., Gasteyer, S., Keating, K., \& Pigg, K. (2012). Community leadership development education: Promoting civic engagement through human and social capital. Community Development, 43(1), 31-48. doi: http://dx.doi.org/10.1080/15575330.2011.645043

Bishop, M., Press, A., \& Tauber, T. (2010). Economics: An A-Z guide. London: Profile Books Ltd.

Botes, L., \& van Rensburg, D. (2000). Community participation in development: Nine plagues and twelve commandments. Community Development Journal, 35(1), 41-58. doi: http://dx.doi.org/10.1093/cdj/35.1.41 
Bourdieu, P. (1986). The forms of capital. In J. Richardson (Ed.), Handbook of theory and research for the sociology of education (pp. 241-258). NY: Greenwood.

Coleman, J. S. (1988). Social capital in the creation of human capital. American Journal of Sociology, 94, S95-S120. doi: http://dx.doi.org/10.1086/228943

Davis, T. S., \& Cooper, H. S. (2014). Using concept mapping for assessment and planning in rural communities: Identifying capacities through participation. In T. L. Scale, C.L. Streeter \& H.S. Cooper (Eds.), Rural social work: Building and sustaining community capacity ( $2^{\text {nd }}$ ed., pp. 281-301). Hoboken, NJ: Wiley.

Dominguez, S. (2008). Social capital. In T. Mizrahi \& L.E. Davis (Eds.), Encyclopedia of social work $\left(20^{\text {th }}\right.$ ed.). Oxford University Press. Retrieved from http://www.oxfordreference.com/view/http://dx.doi.org/10.1093/acref/978019530661 3.001.0001/acref-9780195306613-e-361?rskey=pwaiou\&result=361

Emery, M., Fernandez, E., Gutierrez-Montes, I., \& Flora, C. (2009). Leadership as community capacity building: A study on the impact of leadership development training on community. Community Development, 38(4), 60-70. doi: http://dx.doi.org/10.1080/15575330709489819

Emery, M., \& Flora, C. (2009): Spiraling-up: Mapping community transformation with community capitals framework. Community Development, 37(1), 19-35. doi: http://dx.doi.org/10.1080/15575330609490152

Flora, C., \& Flora, J. (2013). Rural communities: Legacy and change ( $4^{\text {th }}$ ed.). Boulder, CO: Westview.

Gaunt, T. P. (1998). Communication, social networks, and influence in citizen participation. Community Development, 29(2), 276-297. doi: http://dx.doi.org/10.1080/15575339809489765

Hawkins, R. L., \& Maurer, K. (2012). Unravelling social capital: Disentangling a concept for social work. British Journal of Social Work, 42, 353-370. doi: http://dx.doi.org/10.1093/bjsw/bcr056

Healy, K., \& Hampshire, A. (2002). Social capital: A useful concept for social work? Australian Social Work, 55(3), 227-238. doi: http://dx.doi.org/10.1080/03124070208410978

Kane, M., \& Trochim, W. M. K. (2007). Concept mapping for planning and evaluation. Thousand Oaks, CA: Sage.

Kretzmann, J. P., \& McKnight, J. L. (1993). Building communities from the inside out: A path toward finding and mobilizing a community's assets. Evanston, IL: Kretzmann \& McKnight.

Lachapelle, P. (2009). A sense of ownership in community development: Understanding the potential for participation in community planning efforts. Community Development, 39(2), 52-59. doi: http://dx.doi.org/10.1080/15575330809489730

Mannarini, T., \& Talò, C. (2013). Evaluating public participation: Instruments and 
implications for citizen involvement. Community Development, 44(2), 239-256. doi: http://dx.doi.org/10.1080/15575330.2012.683799

Overcamp-Martini, M. (2008). Theory for the public good? Social capital theory in social work education. Advances in Social Work, 8(1), 196-207.

Putnam, R. D. (2000). Bowling alone: The collapse and revival or American community. New York, NY: Simon \& Schuster.

Putnam, R. D., \& Feldstein, L. M. (2003). Better together: Restoring the American community. New York, NY: Simon \& Schuster. doi: http://dx.doi.org/10.1145/358916.361990

Trochim, W. M. K., Milstein, B., Wood, B. J., Jackson, S., \& Pressler, V. (2004). Setting objectives for community and systems changes: An application of concept mapping for planning a statewide health improvement initiative. Health Promotion Practice, 5 (1), 8-19. doi: http://dx.doi.org/10.1177/1524839903258020

Woolcock, M. (2001). The place of social capital in understanding social and economic outcomes. ISUMA Canadian Journal of Policy Research, 2(1), 11-17.

Woolcock, M., \& Narayan, D. (2000). Social capital: Implications for development theory, research, and policy. The World Bank Research Observer, 15(2), 225-249. doi: http://dx.doi.org/10.1093/wbro/15.2.225

\section{Author note}

Address correspondence: Kyle A. Pitzer, MSSW, Washington University in St. Louis, George Warren Brown School of Social Work, Campus Box 1196, 1 Brookings Dr., St. Louis, MO 63130. Email: kyleapitzer@wustl.edu 